\title{
ARTIGO
}

\section{O EFEITO DO CAPITAL ESCOLAR NO ACESSO AO PROGRAMA CIÊNCIA SEM FRONTEIRAS}

\author{
THE EFFECT OF SCHOOL CAPITAL ON ACCESS TO \\ PROGRAM SCIENCE WITHOUT BORDERS PROGRAM
}

\author{
EL EFECTO DEL CAPITAL ESCOLAR EN EL ACCESO AO \\ PROGRAM CIENCIA SIN FRONTERAS
}

Catarina Barbosa Torres Gomes ${ }^{1}$

\begin{abstract}
RESUMO
Este artigo aborda possíveis efeitos do capital escolar no acesso à mobilidade acadêmica internacional ofertada pelo programa Ciência sem Fronteiras ${ }^{2}$, e tem como objetivo analisar a influência tanto do passado escolar na determinação de um perfil ideal para a mobilidade acadêmica quanto do percurso escolar e de experiências de mobilidade nessa trajetória. Em síntese, a intenção é a de verificar a hipótese de estarmos diante de uma "elite escolar", composta por sujeitos que passaram por um rigoroso processo de seleção escolar que, por meio de investimentos familiares e pessoais, tiveram as condições requeridas para o acesso a esse tipo de mobilidade. Tanto no contexto internacional, sobretudo na Europa, em função da amplitude do programa Erasmus, quanto no Brasil, o tema tem ganhado espaço, sobretudo após o advento do CsF, o que evidencia sua importância no cenário das políticas educacionais mundiais. A metodologia de análise fundamentou-se nos parâmetros da amostragem aleatória simples e análise de conteúdo. Os resultados comprovaram a hipótese de que o perfil do estudante considerado apto à mobilidade, sobretudo selecionado com as bolsas para instituições mais concorridas também tinham uma trajetória escolar sem percalços, até mesmo no contexto universitário. Muitos eram ligados às atividades de iniciação científica, monitoria e extensão universitária.
\end{abstract}

PALAVRAS-CHAVE: Capital Escolar. Mobilidade Acadêmica Internacional. Programa Ciência sem Fronteiras. Desigualdade.

\begin{abstract}
This article discusses possible effects of school capital on access to international academic mobility offered by Science without Borders program, and aims to analyze the influence of both the school past in determining an ideal profile for academic mobility as well as school experience and mobility experiences in this trajectory. In summary, the intention is to verify the hypothesis of being in front of a "school elite", composed of resistant subjects of a rigorous process of school selection that, through parental and personal investments, had the requisite conditions for access to mobility. Both in the international context, especially in Europe, due to the extent of the Erasmus program, and in Brazil, the subject has been the subject of research, which shows its importance in the scenario of global educational policies. The analysis methodology was based on the parameters of simple random sampling and content analysis. The results confirmed the hypothesis that the profile of the student considered apt for mobility, especially selected with the scholarships to more crowded institutions also had a school trajectory without mishaps, even in the university context. Many were linked to the activities of scientific initiation, monitoring, and university extension.
\end{abstract}

KEYWORDS: School Capital. International Academic Mobility. Science without Borders Program. Inequality.

\footnotetext{
${ }^{1}$ Doutora em Educação - Universidade Federal de Minas Gerais - (UFMG). Belo Horizonte, MG - Brasil. Professora de Filosofia, Sociologia e Licenciaturas - Centro Federal de Educação Tecnológica (CEFET). Belo Horizonte, MG - Brasil. E-mail: catbtorres@hotmail.com

2 Será designado como CsF nas próximas referências.

Submetido em: 13/02/2019 - Aceito em: 06/07/2019
}

(C) ETD- Educação Temática Digital

Campinas, SP

v. 22

n.2

p. $336-353$

abr./jun.2020 


\section{RESUMEN}

Este artículo considera posibles efectos del capital escolar en el acceso a la movilidad académica internacional ofrecida por el Programa Ciencia sin Fronteras, y tiene como objetivo analizar la influencia tanto del pasado escolar en la determinación de un perfil ideal para la movilidad académica como del recorrido escolar y de experiencias de movilidad en esa trayectoria. En síntesis, la intención es la de verificar la hipótesis de estar ante una "elite escolar", compuesta por sujetos sobrevivientes de un riguroso proceso de selección escolar que, por medio de inversiones parentales y personales, tuvieron las condiciones requeridas para el acceso a este tipo de movilidad. Tanto en el contexto internacional, sobre todo en Europa, en función de la amplitud del programa Erasmus, como en Brasil, el tema ha ganado espacio, sobre todo tras el advenimiento del programa "Ciencia sin fronteras, lo que pone de relieve su importancia en el escenario de las políticas educativas mundiales. La metodología de análisis se basó en los parámetros del muestreo aleatorio simple y análisis de contenido. Los resultados comprobaron la hipótesis de que el perfil del estudiante considerado apto a la movilidad, sobre todo seleccionado con las becas para instituciones más concurridas, también tenían una trayectoria escolar sin percances, incluso en el contexto universitario. Muchos estaban ligados a las actividades de iniciación científica, monitoreo y extensión universitaria.

PALABRAS CLAVE: Capital Escolar. Movilidad Académica Internacional. Programa de Ciencia sin Fronteras. Desigualdad.

\section{INTRODUÇÃO}

Esse trabalho apresenta resultados de uma pesquisa de doutorado ${ }^{3}$, realizada na $U_{F M G}{ }^{4}$, e que examinou a relação entre o acesso à mobilidade internacional para fins de formação acadêmica e o perfil sociológico do beneficiário da bolsa do Programa CsF. O pressuposto principal é o de que as oportunidades educacionais, em nosso País, são diferentes e se refletiram na obtenção da bolsa. A questão norteadora desse trabalho indaga o perfil prioritário do Programa CsF. Seria esse estudante detentor de um capital escolar que se refletiu em vantagens sociais, corroborando com a sua seleção como bolsista do Programa? A abordagem é orientada pelas discussões do campo teórico da Sociologia da Educação, a qual examina o fenômeno, tanto na perspectiva das desigualdades presentes nas mobilidades estudantis nacionais, quanto internacionais. No caso do Programa CsF, estaríamos corroborando o diagnóstico feito por Ballatore e Blöss (2008b, p.45) para definir os estudantes europeus que participam do Programa Erasmus, e promovendo o acesso a um benefício público a uma exclusiva "população socialmente favorecida e escolarmente selecionada"?

\footnotetext{
${ }^{3}$ A tese foi realizada no período de 2013 a 2016. Portanto, com o Programa CsF em curso. Para tanto, contouse com o apoio da Diretoria de Relações Internacionais (DRI) para a obtenção dos contatos dos estudantes. Do mesmo modo houve uma importante colaboração de Alice Lopes - doutoranda da Universidade de Edimburgo - no acesso aos dados que compõem a planilha contendo o nome dos estudantes intercambistas do CsF pela UFMG e de Bréscia França Nonato, doutoranda da Faculdade de Educação da UFMG, pelo compartilhamento dos dados da Prograd/Copeve/UFMG.

${ }^{4}$ A opção pela UFMG ocorreu em função de três fatores: trata-se da maior universidade de Minas, além de ser a instituição que mais enviou estudantes ao CsF no estado de Minas Gerais, ocupando a vice-liderança no país. Ademais, o acesso aos dados dessa Instituição foi fundamental para a adoção desse recorte. Tais dados são mencionados na metodologia informada nesse artigo. A UFMG tem uma Diretoria de Relações Internacionais muito ampla e organizada, com uma história institucional que possibilita a consulta de dados.
}

(C) ETD-Educação Temática Digital

Campinas, SP

v.22

n.2

p. $336-353$

abr./jun.2020 


\section{1 O Programa Ciência Sem Fronteiras}

A intensificação e sistematização da mobilidade internacional têm sido registradas apenas a partir do séc. XX no cenário de reconstrução europeu, logo após a segunda grande guerra. Esse fenômeno acentuou-se mundialmente no decorrer do séc. XX e, no Brasil, se intensificou algumas décadas após a criação das primeiras universidades. O quadro da mobilidade acadêmica internacional no Brasil se ampliou, após a criação, em 2011, do Programa CSF situando-se em um patamar mais abrangente, tanto pela quantidade de vagas quanto pelo financiamento, e correspondeu a uma estratégia nacional de adequação às políticas econômicas globais, ao mercado mundial de bens e serviços e às exigências do mundo do trabalho.

O Programa consistiu em atividades de cooperação internacional e na concessão de bolsas de estudos no exterior, operacionalizadas no âmbito da Coordenação de Aperfeiçoamento de Pessoal de Nível Superior (CAPES) e do Ministério da Educação (MEC) em parceria com o Conselho Nacional de Desenvolvimento Científico e Tecnológico (CNPq). Trata-se de uma política de Estratégia Nacional de Ciência, Tecnologia e Inovação (ENCTI) desenvolvida no período de 2012-2015. Sua meta inicial do Programa era a de distribuir 101 mil bolsas, em quatro anos, para estudantes universitários de diferentes níveis: graduação, pós-graduação e estágio pós-doutoral. O maior número de bolsas foi reservado para a graduação, restritas às áreas de estudo consideradas "prioritárias" ${ }^{5}$, distribuídas entre as ciências exatas, naturais e a tecnológicas.

A Capes estabelecera que para participar do Programa as instituições universitárias, previamente inscritas dentro dos parâmetros exigidos, deveriam apresentar propostas para os editais abertos pelo MEC, arrolando os cursos que pretendiam incluir. Após a avaliação, as universidades com suas propostas aprovadas receberam, para cada curso participante, um número de bolsas com o fim de enviar os seus estudantes às universidades estrangeiras.

O processo de seleção dos estudantes dependeria de editais próprios, destinados às chamadas publicadas pelas respectivas agências. Às Instituições de Ensino Superior (IES), caberia orientar os estudantes, além de conferir a existência dos requisitos indispensáveis às inscrições, tais como: matrícula, curso de origem, histórico e desempenho que, no caso

\footnotetext{
${ }^{5}$ Áreas Prioritárias do Programa CsF: Engenharias e demais áreas tecnológicas; Ciências Exatas e da Terra; Biologia, Ciências biomédicas e da Saúde; Computação e Tecnologias da Informação; Tecnologia Aeroespacial; Fármacos; Produção Agrícola Sustentável; Petróleo, Gás e Carvão Mineral; Energias Renováveis; Tecnologia Mineral; Biotecnologia; Nanotecnologia e Novos Materiais; Tecnologias de Prevenção e Mitigação de Desastres Naturais; Biodiversidade e Bioprospecção; Ciências do Mar; Indústria Criativa (objetiva a criação de produtos e processos para desenvolvimento tecnológico e inovação); Novas Tecnologias de Engenharia Construtiva; Formação de Tecnólogos.
} 
específico da UFMG, foi analisado com base no rendimento semestral global (RSG). ${ }^{6}$ Além disso, o estudante deveria se submeter a uma avaliação em língua estrangeira, que poderia ser o inglês ou a língua nativa do país de destino. ${ }^{7}$ A nota dessa avaliação seria agregada aos demais dados de inscrição. A homologação dos resultados, beneficiando o estudante com uma bolsa do CsF, dependeria, então, de três fatores: 1- A comprovação de satisfação dos requisitos exigidos; 2- O êxito obtido no exame de proficiência em língua estrangeira; 3- o desempenho obtido no Exame Nacional do Ensino Médio (ENEM) ${ }^{8}$. O perfil preferencial do CsF visava alcançar os estudantes bolsistas de Iniciação Científica e premiados em olimpíadas de conhecimento. Após esse processo e análise das respectivas agências, os beneficiários do Programa seriam divulgados no site do Programa.

\section{MARCO TEÓRICO: CONCEITUANDO O “CAPITAL ESCOLAR”}

Articular o perfil ao capital escolar do estudante é uma tarefa que, de acordo com Nogueira (2004), demanda o entendimento da noção de trajetória escolar como um "encadeamento temporal de posições sucessivamente ocupadas pelos indivíduos nos diferentes campos do espaço educacional" (p.135). Admitindo a composição de uma biografia escolar capaz de determinar indicadores do acúmulo do capital escolar, essa autora considera que na raiz das trajetórias escolares individuais, residem as práticas de socialização e de acompanhamento da escolaridade, sobre o modo como as famílias transmitem valores e admitem as práticas educativas, tendo em vista a construção de projetos, bem como a "escolha" dos estabelecimentos de ensino, incluindo o acompanhamento da escolaridade pelos pais e, até mesmo, a demanda por cursos particulares (NOGUEIRA, 2004 e DAVERNE, 2011).

Com o intento de problematizar a relação entre as biografias escolares dos estudantes selecionados no contexto das mobilidades acadêmicas, ofertada pelo CsF, pergunta-se: Quais as disposições escolares dos beneficiados? Há, entre eles, acúmulo sob a forma de capital escolar, entendido sucesso ou bom rendimento escolar? As exigências do Programa CsF para a seleção do estudante implicam necessariamente o reconhecimento de que o capital escolar teria um papel determinante na aprovação das candidaturas paras as bolsas. $O$ desempenho escolar demonstrado a partir do rendimento semestral global, no caso da UFMG, associado à obtenção de prêmios e distinções acadêmicas devem corroborar a hipótese de que há uma "elite escolar", composta por sujeitos sobreviventes de um feroz processo de seleção

\footnotetext{
${ }^{6}$ O RSG é um recurso utilizado pelo Diretório de Registro Acadêmico da UFMG (DRCA) calculado da seguinte forma: o valor do conceito de cada disciplina cursada no semestre, multiplicado pelo respectivo número de créditos. Estes produtos são somados e o resultado é dividido pelo número total de créditos matriculados no semestre. Fonte: Diretório de Registro Acadêmico da UFMG (DRCA, 2014).

${ }^{7}$ Exceto para Portugal, cujo convênio foi interrompido em abril de 2013.

8 Ressalta-se que, até meados de 2013, a nota obtida nesse exame era considerada apenas para fins classificatórios. Após esse período, ela passou a representar um critério eliminatório, tornando-se requisito indispensável. (CNPq, 2014, p.300).
} 
(escolar), nos termos formulados por Xavier de Brito (2005), mas que, para tanto, dispôs desde cedo, por meio de investimentos familiares e pessoais, das condições requeridas para o acesso a um bem educacional ainda raro entre a maioria dos brasileiros.

A noção de capital escolar implica o reconhecimento "dos itinerários percorridos por estudantes universitários brasileiros provenientes das camadas médias intelectualizadas e as estratégias praticadas por esses e, por suas famílias, no decorrer de sua formação escolar" (NOGUEIRA, 2011, p.127). Constituem evidências empíricas desse fenômeno: o fluxo das trajetórias escolares; as redes de ensino e os estabelecimentos frequentados; o momento do vestibular; a vida acadêmica e os estudos no exterior.

Assim como Daverne (2011) atribui um papel fundamental à aquisição das disposições escolares, sem percalços, Nogueira (2011), considera que o "fluxo das trajetórias" calcado pela determinação do capital escolar se baseia na fluência e linearidade dos percursos escolares, sem intercorrências que possam acarretar atrasos na progressão do estudante dentro do sistema escolar. A coordenação entre bom desempenho e bom aproveitamento do tempo escolar resulta em evidência empírica de um trajeto escolar fluente que impacta positivamente a idade de entrada na universidade.

Portanto, o capital escolar é um recurso predisponente para a mobilidade por ser característico do perfil de um estudante cuja escolarização constitui, dentre outras possibilidades, uma preparação para o desafio das fronteiras. Ballatore e Blöss (2008) revelam que a influência desse capital opera, especialmente, no sentido de delimitar as chances dos interessados na mobilidade, influenciando em várias etapas da seleção, desde o destino até as formas de instalação na instituição universitária e no país escolhidos. Embora se acredite que os candidatos ao intercâmbio internacional sejam selecionados de acordo com princípios meritocráticos (alto nível de performance escolar, autodisciplina nos estudos etc.), esses autores acreditam que essa característica se acresce, em especial, dos efeitos das vantagens sociais de que os estudantes dispõem. Ballatore (2011) e Ballatore e Blöss (2008a) demonstram - com base em pesquisa do Observatoire Universitaire Régionale de l'insertion professionnelle (OURIP) na França - que os estudantes Erasmus são mais precoces na vida escolar e estão mais avançados nos estudos do que o conjunto de seus pares. Do mesmo modo, Erlich (2012) afirma que "quanto mais jovem for o estudante que se candidatar ao Erasmus, maior será sua chance de ser aceito porque concluiu com antecipação uma formação que, a rigor, demandaria maior tempo" (p.111). Essa precocidade revela o perfil de um estudante com disposições escolares acima da média que o qualifica como ótimo ou excelente. 


\section{METODOLOGIA}

\subsection{Tipo de Estudo, a População da Pesquisa e Procedimentos para a coleta de dados}

O presente estudo é quantiqualitativo, e resulta da análise de conteúdo de um conjunto de depoimentos escritos. A população pesquisada consiste de um universo de 1538 estudantes dos cursos de Graduação da UFMG, pertencentes a todas as áreas prioritárias, os quais se beneficiaram de bolsa do Programa CsF no ano de 2013 (com término do intercâmbio previsto para 2014), em resposta aos editais da CAPES e do CNPq. O planejamento da pesquisa empírica implicou na definição de duas frentes de trabalho para a coleta de dados. A primeira, consistiu na coleta de dados secundários da PROGRAD/COPEVE/UFMG e do banco nacional de dados do CNPq, e a segunda, consistiu na produção de dados primários, por meio da aplicação de um questionário - com questões fechadas e abertas - a uma amostra extraída do universo acima mencionado.

\subsubsection{A coleta e análise de dados primários e secundários}

Os dados primários foram obtidos diretamente com os sujeitos da investigação, por meio de um questionário com 26 questões fechadas e 34 questões abertas, aplicados a uma amostra dessa população, extraída a partir de "Amostragem Aleatória Simples". ${ }^{9}$ Ressalta-se que o que define a amostragem simples são as características homogêneas da população pesquisada. Ex: todos são estudantes da UFMG; são estudantes que participaram de um mesmo programa de mobilidade; fazem parte do mesmo recorte temporal. Desse modo, a amostra principal da pesquisa constituiu-se de 508 estudantes que responderam o questionário. As primeiras questões inventariadas tiveram a finalidade de captar informações para que se pudesse traçar o perfil sociológico do beneficiário do Programa. Para cada estudante foram levantadas informações sobre seu capital escolar.

As questões abertas tiveram a finalidade de detalhar e complementar as informações obtidas na parte fechada do questionário e foram estruturadas em três blocos. O primeiro bloco abordou a formação complementar do estudante de modo qualitativo, enfocando questões como: sua vida extra-escolar; relação com pesquisas e com idiomas, e em particular, com a língua do país de destino etc. O segundo bloco tratou de sua experiência com o Programa CsF: primeiros contatos, desempenho no processo seletivo, disposições, apoio da família e de outros próximos, ajuda financeira, etc. No terceiro bloco foram abordadas as disposições dos estudantes, suas motivações e expectativas para a realização de um intercâmbio.

\footnotetext{
${ }^{9}$ Os entrevistados responderam aos questionários por meio de formulários automáticos do Google Drive.
} 
A coleta de dados secundários realizou-se por meio do acesso a um Data mart nacional do $\mathrm{CNPq}$, o qual continha o cadastro de todos os alunos beneficiados com a bolsa para participar Programa CsF, no período de 2012 a 2013, contendo uma planilha com dados (nome, sexo, curso de origem, área prioritária, duração do intercâmbio, país e instituição de destino) dos estudantes da UFMG que ingressaram no CsF no ano de 2013 ( $N=1538$ ) e que se tornaram nosso universo inicial de sujeitos. A partir dessa planilha, obtivemos - junto à Diretoria de Relações Internacionais da UFMG - os endereços eletrônicos desses estudantes, possibilitando assim a posterior realização da coleta de dados primários.

\subsection{A Análise de Dados}

As pesquisas qualitativas assumem "valores" em categorias ou classes e a análise dos dados fundamentam-se em técnicas de análise de conteúdo, conforme Laurence Bardin (1979). Para traçar o perfil social dos pesquisados realizou-se uma comparação com grupos de referência: os discentes matriculados na UFMG em 2013. Devido ao fato desse grande grupo ser composto por estudantes ligados a várias áreas do conhecimento, incluindo as ciências humanas e sociais, não contempladas pelo CsF, optou-se por estabelecer um grupo de controle, formado pela área predominante no Programa, que é a "engenharia". Uma vez estabelecido esse parâmetro para comparação, tornou-se possível analisar se o pesquisado teria ou não um perfil socialmente selecionado e escolarmente favorecido frente ao seu grupo de origem (discentes da UFMG) e frente ao grupo majoritário no CsF (discentes das Engenharias). Para tanto, aplicou-se análises baseadas em estatística inferencial, cuja metodologia se baseia em um conjunto de técnicas que permite utilizar dados oriundos de uma amostra para generalizações sobre a população. Para quantificação da variabilidade dos dados foi utilizada a distribuição de frequência por meio de tabelas e gráficos.

\section{DISCUSSÃO DOS RESULTADOS}

\subsection{A fração de classe de que se originam}

Considerando que o capital escolar está intrinsecamente relacionado à posição econômica do estudante, apresento traços do perfil socioeconômico dos pesquisados comparado aos grupos de discentes e de engenharias conforme explicitado acima. As variáveis do perfil socioeconômico informaram o capital econômico familiar, o pertencimento racial, o número de filhos nas famílias, o local de moradia, a profissão e o nível de escolaridade dos pais. Ademais, coube analisar se os pesquisados exerciam atividades remuneradas durante a vida acadêmica.

O perfil socioeconômico do conjunto dos estudantes da UFMG no ano do estudo revelou um percentual de baixa renda mais expressivo em comparação com a fração composta pelos estudantes de engenharia, dos quais, $68 \%$ ocupavam a faixa acima de $5 \mathrm{SM}$, indicando que esse grupo seria mais favorecido do que o conjunto dos estudantes que entrou 
na UFMG naquele mesmo ano. Contudo, entre os bolsistas do CsF, 75\% dos estudantes informaram uma renda acima de 5SM, o que caracteriza um perfil privilegiado economicamente, inclusive em relação ao grupo das engenharias, que já possui um perfil mais elevado frente à população geral da UFMG.

Os dados referentes à renda familiar mensal do bolsista também foram estratificados por faixas salariais, conforme a classificação dada pela IBGE. A renda familiar mensal dos bolsistas CsF quando enquadrada nos critérios de classificação dos estratos socioeconômicos adotados pelo IBGE revela que $48 \%$ destes pertencem às classes $A$ e $B$, isto é, têm renda familiar mensal acima de $10 \mathrm{SM}$. Na faixa mediana, correspondente à chamada "classe C", estão $27 \%$ deles, enquanto outros $25 \%$ ocupam a faixa salarial mais baixa, podendo ser classificados como pertencentes às classes $\mathrm{D}$ e $\mathrm{E}$.

Quanto ao pertencimento racial dos bolsistas a variável cor foi utilizada em conformidade com a classificação utilizada pelo IBGE para as categorias branca, preta, amarela, parda ou indígena para a obtenção dos dados. Detectou-se uma presença maior de brancos em todos os grupos analisados, a qual se acentua entre os discentes das Engenharias e, ainda mais, entre os pesquisados. No grupo majoritário, $11 \%$ se autodeclararam de cor preta. Entre os estudantes das engenharias esse percentual foi de $8 \%$ sendo que entre os pesquisados do CsF esse percentual ficou restrito a apenas $4 \%$.

O campo das profissões predominantes entre os pais dos pesquisados do CsF é engenharia, empresariado, funcionalismo público, medicina e professor, sendo que mais de $60 \%$ destes possuem ensino superior. Em comparação com os demais grupos (engenharia e discentes em geral) esse percentual relativo à formação acadêmica cai para $43 \%$ e $32 \%$ respectivamente.

A composição das famílias constitui outro ponto interessante para a análise socioeconômica visto que $16 \%$ destas possuem apenas um filho, seguida de $42 \%$ que informaram dois filhos e cerca de $30 \%$ com três filhos. Isso significa que quase $90 \%$ dessas famílias possuem no máximo três filhos. Brito (2008) confirma a tendência de que mulheres com mais filhos, ou famílias mais numerosas, estejam entre as mais pobres.

Do mesmo modo, a correlação entre o local de moradia e o favorecimento social, permitiu observar que os bolsistas pesquisados estão distribuídos por todas as regionais que integram o município de Belo Horizonte, mas de modo muito desigual. Quase todos moram em sua maioria em áreas privilegiadas da cidade, com IDH muito alto (50\%) ou alto (43\%), contra apenas $7 \%$ que residem em áreas de médio IDH.

No que concerne ao exercício de atividade remunerada durante o período de estudo, a comparação entre os discentes da UFMG (2013) e os demais grupos (engenharia e estudantes (SF) revelou que quase $40 \%$ daqueles informaram já terem exercido algum tipo de atividade remunerada. Entretanto, quanto aos estudantes das engenharias essa situação 
torna-se mais incomum, sendo reduzida à metade (20\%) em relação à população geral discente da UFMG. Contudo, o dado mais relevante é aquele informado pelos pesquisados, bolsistas do CsF, que praticamente afirmaram que não exercem ou exerceram nenhum tipo de atividade remunerada ao longo de sua trajetória, o que indica tratar-se de estudantes que gozam de favorecimento econômico, visto que não precisam complementar sua renda. Isso indica dedicação exclusiva aos estudos, o que é bastante comum entre estudantes do turno diurno.

\subsection{Trajetórias Escolares e Acadêmicas}

Esse enfoque fornece as bases para a compreensão do processo de seletividade escolar, quando são analisadas as trajetórias dos bolsistas CsF no que se refere ao ensino fundamental e médio, com base nas respostas que deram às seguintes questões: em que rede de ensino e em qual estabelecimento você cursou o ensino fundamental e médio? Qual a modalidade de seu curso médio? Quantas vezes tentou o vestibular? Com que idade foi aprovado nesse exame? Você fez cursinho pré-vestibular ou pré-Enem? Convém ressaltar que conhecer a rede de ensino frequentada, se pública ou privada, constitui uma evidência empírica que contribui para identificar a origem social dos pesquisados. Aliada a outras variáveis relativas ao passado escolar do estudante, esses dados podem indicar favorecimento social e seleção escolar conforme expressão utilizada por BALLATORE (2011).

A trajetória acadêmica dos pesquisados, apresenta-se por meio dos dados relativos a seu percurso no ensino superior, incluindo a participação no Programa CsF, com base nas respostas às questões: Qual a área prioritária cursada? Em qual turno? Participou de atividades de Iniciação Científica? Participou de olimpíadas de conhecimento? Obteve algum prêmio? Recebeu alguma premiação de origem acadêmica? Qual? A que área prioritária do CsF você pertence? Qual o país e instituição de destino? Identificar tais aspectos das histórias escolares dos pesquisados no decorrer do ensino superior possibilita estabelecer sua relação com a incorporação de diferentes habitus e capitais simbólicos. A análise incide sobre o impacto das trajetórias acadêmicas sobre as chances de acesso à mobilidade internacional como estratégia de incremento da formação recebida, no quadro das disputas travadas em torno do Programa CsF.

\subsubsection{O Ensino Fundamental e Médio e a rede de ensino frequentada}

O estudo dos processos de escolha das redes e dos estabelecimentos de ensino pelas famílias parte do pressuposto de que na estrutura e nas dinâmicas dos sistemas de ensino privados ou públicos - se inscrevem processos de hierarquia, prestígio e presunção de qualidade, os quais influem nas oportunidades educacionais dos indivíduos. No que concerne ao ensino fundamental, um total de $66 \%$ dos pesquisados estudaram em escola privada e, o restante, em escola pública. Tais resultados são totalmente congruentes com aqueles relativos ao ensino médio, tal como apresentado no Gráfico 1. 


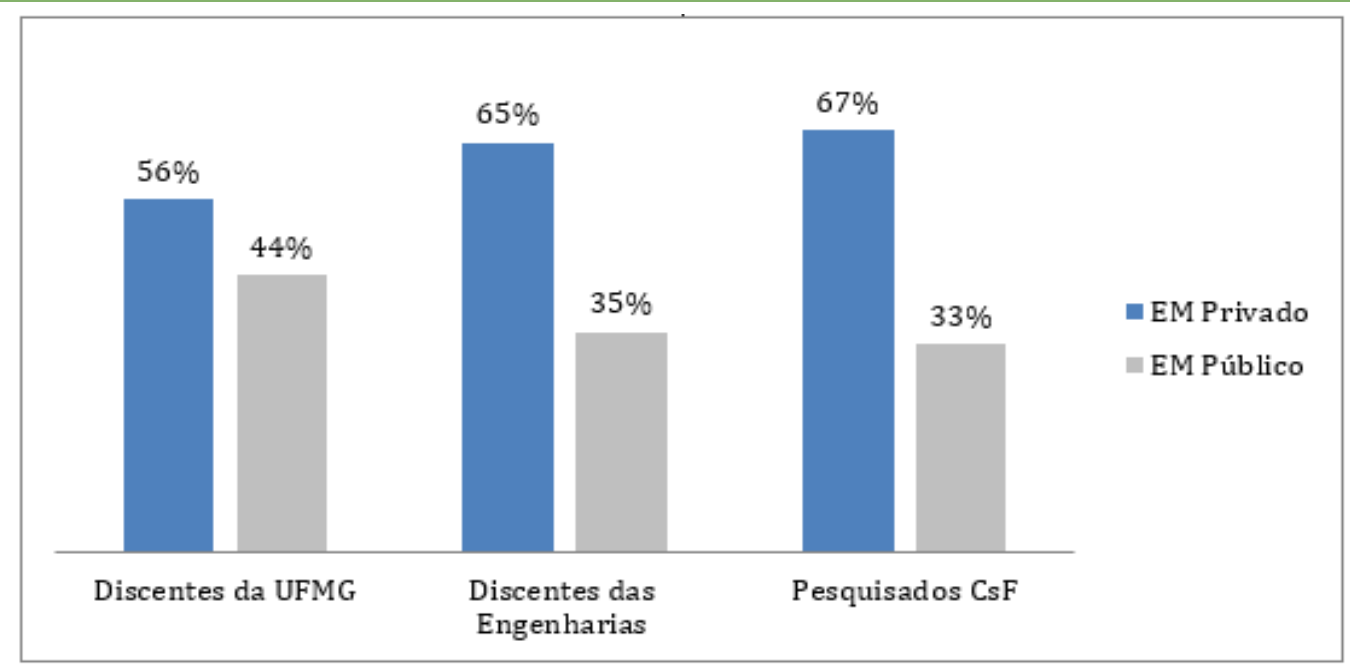

Gráfico 01 - Rede de ensino frequentada no ensino médio pelos discentes da UFMG, das engenharias e pelos estudantes pesquisados em 2013

Fonte: Elaboração própria. Os dados referentes aos discentes da UFMG e da engenharia foram disponibilizados pela COPEVE/PROGRAD/UFMG/2013.

Os estudantes da UFMG são, majoritariamente, egressos do ensino médio privado. No entanto, quando se ajusta o foco sobre cada grupo, diferenças pontuais se acentuam. Enquanto entre os discentes da UFMG há $12 \%$ a mais de egressos do ensino médio privado, no grupo das engenharias essa diferença alcança $30 \%$ e, entre os intercambistas do CsF, $34 \%$. Portanto, embora a população da UFMG seja predominantemente egressa da rede privada de ensino, nas engenharias e entre os pesquisados, a proporção de estudantes é duas vezes mais representativa do que a de origem pública.

Esses resultados indicam uma estreita correlação entre "a origem escolar e o perfil socioeconômico dos estudantes da UFMG" (BRAGA \& PEIXOTO, 2006, p.34), e convergem para uma escolaridade denominada por Nogueira (2011) como do tipo "circuito virtuoso", que se manifesta por um percurso escolar em que a educação básica é cursada em estabelecimentos da rede privada de ensino e o ensino superior é cursado na universidade pública. Uma das razões que explica que a origem social do alunado geral da UFMG seja mais baixa liga-se ao fato de que esse corpo discente é, em parte, oriundo das políticas atuais de ação afirmativa. Além disso, ele está distribuído entre as diversas áreas de conhecimento que incluem carreiras com diferentes graus de seletividade e de prestígio, o que está fortemente correlacionado com vantagens ou desvantagens sociais.

Contudo, há que se salientar, aqui, o caso significativo da parcela de estudantes pesquisados que cursou o ensino médio em escolas públicas federais, como se observa nos dados referentes à escola média pública, conforme o Gráfico 2. 


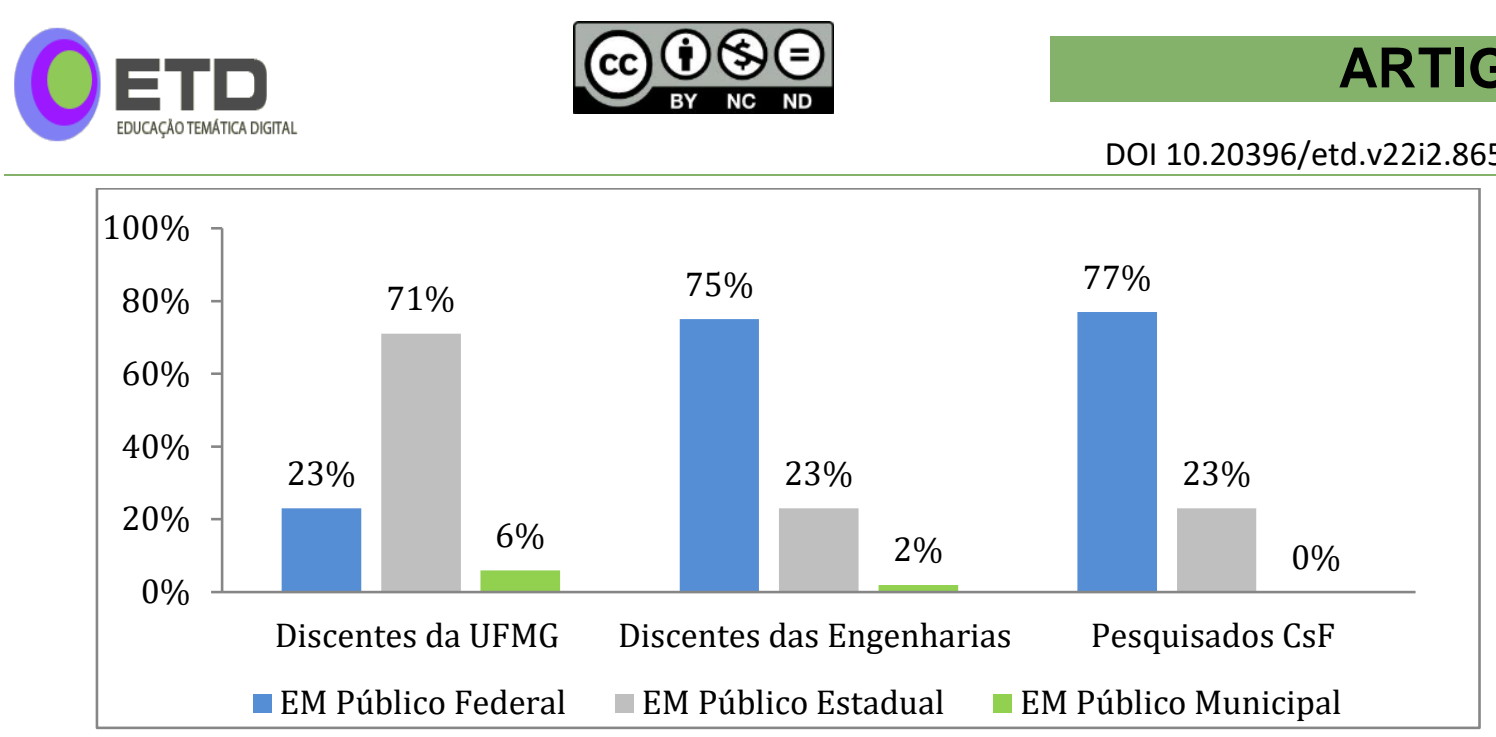

Gráfico 02 - Rede de ensino médio público frequentada pelos discentes da UFMG, das engenharias e pelos pesquisados em 2013

Fonte: Elaboração própria. Os dados referentes aos discentes da UFMG e da engenharia foram disponibilizados pela COPEVE/PROGRAD/UFMG/2015

Os estudantes provenientes de escola pública não estão uniformemente distribuídos entre as escolas municipais, estaduais e federais. Enquanto o corpo discente da UFMG provém, sobretudo, da rede estadual de ensino, nos dois outros grupos focalizados aqui, é nítida a forte predominância de estudantes oriundos de escolas federais (cerca de $3 / 4$ deles). Esse dado torna-se altamente significativo quando se sabe que o ensino médio federal, no conjunto de todas as suas modalidades (escolas técnicas federais, colégios de aplicação, colégios militares etc.) contempla apenas uma ínfima minoria de jovens, cuja taxa de matrícula totalizou 1,7\%, em 2013, na UFMG.

Para Nogueira e Lacerda (2014), as escolas federais gozam de notável prestígio, em função da aprovação de seus egressos em instituições de ensino superior altamente reputadas e seletivas, formando para as carreiras mais valorizadas. Parece, portanto, coerente que seus estudantes - cujos indicadores são "mais favoráveis que os das escolas municipais ou estaduais" (BRAGA \& PEIXOTO, 2006, p.34) - optem por carreiras de alta seletividade, mais prestigiosas e mais rentáveis, como é o caso das engenharias e áreas prioritárias do CsF.

A importância da escolha do estabelecimento de ensino para uma trajetória escolar bem-sucedida implica em esforços da família e muitas vezes em uma clara estratégia para se atingir esse objetivo. Um exemplo disso vem dos relatos de quem revelou ter se mudado de cidade, ou até de estado, para atingi-lo,

Mudei-me para Belo Horizonte para estudar no Magnum Buritis, senti uma grande diferença por se tratar de um ensino com foco bastante veemente no ingresso na universidade. A educação era formatada conforme as regras do vestibular. (Aluna de Comunicação Social- Jornalismo).

Cursei o meu primeiro ano em Vitória-ES e depois decidi vir para BH porque queria tentar UFMG. Estudei dois anos no Promove. Não acho que o ensino lá é particularmente bom, mas sinto que tenho base, sim. Vale ressaltar que eu estudava 
bastante por fora, também, para passar no vestibular. (Aluna de Engenharia de Produção).

Estudei em três escolas no Ensino Médio. No primeiro ano estudei no Pitágoras, no estado do Pará. O nível era abaixo do que desejava para passar na UFMG. Mudei para Belo Horizonte e fiz o segundo ano no colégio Santo Agostinho, muito bom. Porém achava que precisava ir para um ainda melhor. No terceiro ano mudei para o Colégio Santo Antônio e, sem dúvida, ele me deu o suporte necessário para ingressar na UFMG (Aluna do curso de Engenharia Elétrica).

\subsubsection{A modalidade de ensino frequentada}

O ensino - em nível pré-universitário - que profissionaliza costuma ser associado aos setores educacionais de baixo prestígio, segundo Troger (2011). Assim, a representação social dominante é a de que esse tipo de formação não prioriza o prosseguimento dos estudos no nível superior ao passo que os estudos secundários acadêmicos se voltariam a uma minoria destinada às carreiras superiores de alto prestígio e renda.

No entanto, uma exceção a essa regra deve ser aqui considerada: é o caso das escolas técnicas federais que oferecem uma formação de nível médio integrada à qualificação técnica e que, como se viu no tópico anterior, têm despontado entre as instituições públicas que se destacam nos rankings anuais do ENEM. Segundo Schwartzman e Castro (2013, p.581), os CEFETs têm tradição na preparação de estudantes para o "ingresso nas universidades mais competitivas, atendendo predominantemente a estudantes de classes média e alta que conseguem acesso através de exames de seleção, os 'vestibulinhos'". Nesse quesito e no que tange à população aqui investigada, temos o seguinte quadro, expresso no Gráfico 3.

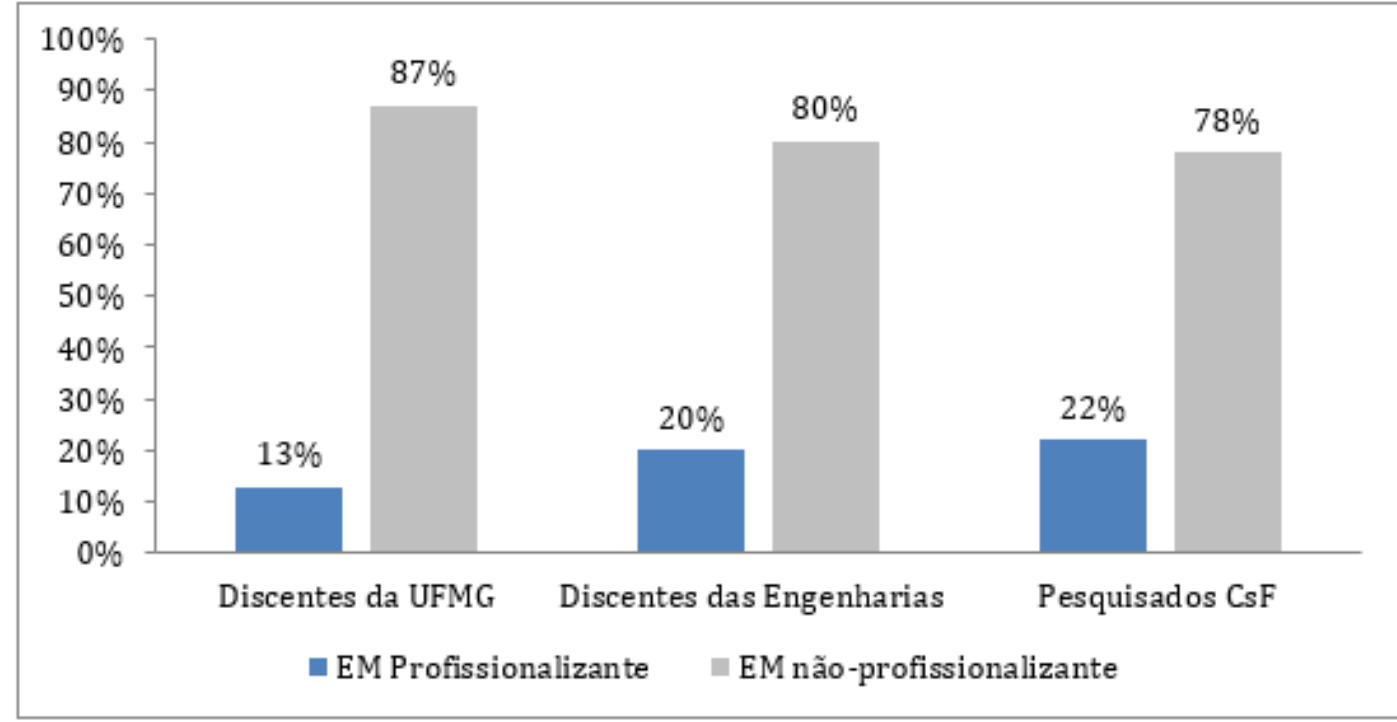

Gráfico 03 - Modalidade de ensino médio frequentada pelos discentes da UFMG, das engenharias e pelos pesquisados em 2013

Fonte: Elaboração própria. Os dados referentes aos discentes da UFMG e das engenharias foram disponibilizados pela COPEVE/PROGRAD/UFMG/2013. 
O ensino médio não-profissionalizante predomina nos três grupos analisados. Entretanto, entre os discentes da UFMG, o percentual de estudantes provenientes do ensino profissionalizante é menos expressivo do que entre o alunado das engenharias e entre os bolsistas do CsF pesquisados. Mas o que explicaria esse fato se considera a natureza desprivilegiada desse tipo de ensino em oposição ao favorecimento social dos dois últimos grupos já constatado anteriormente? A hipótese explicativa mais plausível parece se relacionar com o fato de que a formação profissionalizante ofertada pelas escolas técnicas federais são alvo cobiçado e efetivamente utilizado por grupos sociais relativamente favorecidos, como meio de acesso às instituições e aos cursos universitários de maior prestígio, como é o caso das engenharias que, por sua vez, fornece o grosso do contingente dos bolsistas CsF. Assim, a boa reputação das escolas federais responde pela inclusão de seus egressos nas áreas da ciência e tecnologia hoje mais valorizadas do que as ciências humanas e sociais

\section{A TRANSIÇÃO PARA O ENSINO SUPERIOR}

5.1 As tentativas e a idade de ingresso na UFMG (houve aglutinação dos títulos e supressão dos gráficos)

No que concerne ao ingresso na UFMG e seu êxito, pode-se afirmar que apenas $15 \%$ dos discentes da UFMG obtiveram sucesso na primeira tentativa. Todavia, entre os discentes das Engenharias, essa taxa mais que dobra elevando-se a 32\% dos calouros, e atingindo $75 \%$ dos pesquisados do Programa CsF, numa clara demonstração de trajetória escolar exitosa. Há que se lembrar aqui que os estudos sociológicos sobre as trajetórias escolares em diferentes meios sociais já consagraram a tese de que a precocidade das realizações educacionais eleva fortemente a probabilidade de atingir a "excelência escolar" nos termos de Nogueira, (2004).

Em conjunto com o número de tentativas de ingresso na universidade, a idade de aprovação no vestibular constitui um forte indício de um percurso escolar intercorrências. Como sublinha Nogueira (2011), a fluência do itinerário escolar caracteriza a ausência de problemas como repetência ou interrupção dos estudos. Entre os pesquisados, houve amplo predomínio da aprovação no vestibular da UFMG na faixa etária de 17 a 18 anos de idade. Essa larga inserção de jovens na universidade imediatamente após a conclusão do ensino médio deixa claro um passado escolar regular, sem percalços.

\subsection{O Ensino Superior: O turno frequentado}

O fator "turno" de estudos (diurno ou noturno) sempre foi amplamente associado pela literatura sociológica à origem social dos alunos. É, portanto, um fenômeno fortemente articulado a indicadores socioeconômicos e ao próprio desempenho escolar. Estudar no período noturno constituiria, assim, "uma séria desvantagem na corrida pelos títulos 
escolares, efeito que não escapa certamente aos pais pertencentes aos meios culturalmente favorecidos, os quais se mostram dispostos a todo tipo de sacrifício para que o destino escolar dos filhos não corra riscos" (NOGUEIRA, 2011, p.144).

Em todos os grupos examinados, restou clara a predominância de estudantes que estudam/estudaram no período diurno. Adachi (2009) afirma que os candidatos ao ensino noturno da UFMG são oriundos da classe média baixa e da rede pública de ensino. Dias et al. (2008), por sua vez, afirmam que as barreiras socioeconômicas são decisivas para que os jovens optem pelo turno da noite. Para esses pesquisadores, muitos desses estudantes combinam uma rotina diária de trabalho com os estudos, apresentando uma inserção precoce no mercado de trabalho. É plausível, portanto, inferir que boa parte dos estudantes do turno noturno da UFMG tenha se autoexcluído da disputa pela bolsa do Programa CsF, em função de sua condição socioeconômica e financeira ${ }^{10}$; mas também de disposições relacionadas às experiências de mobilidade. Sem poder contar com os investimentos escolares típicos das famílias de classe média, incluindo a possibilidade precoce da "internacionalização da formação", como discute Nogueira (2010), é pouco provável que estudantes desfavorecidos, como os do turno noturno, obtivessem êxito na disputa pelas bolsas do CsF.

\subsection{As carreiras universitárias frente à perspectiva do intercâmbio}

Apenas três áreas prioritárias do CSF concentraram em torno de $80 \%$ das bolsas concedidas no ano de 2013, embora haja uma considerável variação entre elas. Da primeira colocada (Engenharias e demais áreas tecnológicas) para a segunda (Biologia, Ciências Biomédicas e da Saúde) a diferença é de 33\%, enquanto que desta para a terceira (Indústria Criativa) é de apenas $5 \%$. A hipótese mais provável para a variação do percentual de bolsas entre as áreas poderia ser justificada pelo alto grau de afinidade dos estudantes das engenharias com os objetivos e metas do Programa, associado às condições favoráveis desses estudantes para disputar as bolsas, constituiu-se no principal fator para que essa área se destacasse em relação às outras. De acordo com Braga e Peixoto, (2006, p.34) as carreiras de alta seletividade, mais prestigiosas e mais rentáveis, são escolhas que envolvem engenharias e áreas prioritárias do CsF.

Os bolsistas pesquisados mencionaram explicitamente o impacto dos estudos internacionais proporcionados pelo CsF na profissão e carreira. A essa perspectiva, acrescentaram-se o reconhecimento de que se trata de uma oportunidade de crescimento pessoal, acentuando a relevância do intercâmbio como um importante degrau para seu desenvolvimento acadêmico e cultural. Para eles, o impacto desse processo de internacionalização da formação é também uma experiência extremamente positiva e

\footnotetext{
${ }^{10}$ No início do Programa CsF, os exames de proficiência em língua estrangeira eram pagos e custavam por volta de $\mathrm{R} \$ 500,00$.
} 
promissora para a carreira profissional, concebida em articulação com a condição do desempenho pessoal e acadêmico.

\subsubsection{A Iniciação Científica e os prêmios recebidos}

No contexto desta pesquisa, $42 \%$ dos pesquisados se enquadram no perfil preferencial do CsF, já que $31 \%$ dos bolsistas passaram pela experiência da Iniciação Científica (IC), e $11 \%$ receberam algum tipo de prêmio de natureza acadêmica, no decorrer de seus estudos universitários. Definido como um critério preferencial para a admissão no CsF, a participação em atividades de Iniciação Científica constitui um bem educacional de grande demanda e reduzida oferta, o que acarreta uma forte concorrência no campo acadêmico.

A obtenção desse bem raro e distintivo prepara para a carreira científica e capacita para as disputas do campo acadêmico, tal como a disputa pela bolsa CsF. Daí decorrem a aprendizagem e a experiência de práticas de pesquisa e, portanto, a incorporação de um habitus de pesquisador que se forja na transmissão e recepção de valores, atitudes e comportamentos do grupo e do campo de pesquisa.

Fiz duas pesquisas de Iniciação Cientifica: uma no Departamento de Química e outra no Departamento de Engenharia Química da UFMG. Já tinha contato com pesquisa por influência de meus pais. Fui membro da Mult. Jr, empresa júnior do curso de Engenharia Química da UFMG, e fui professora voluntária de inglês no cursinho popular Equalizar. (Aluna da Engenharia Química).

Já recebi prêmios dentro do programa da UFMG da Semana do Conhecimento em um projeto de Monitoria e em outro projeto de iniciação científica. (Aluno de Medicina).

Fui medalhista de prata na Olimpíada Brasileira de Matemática das Escolas Públicas,

medalhista de prata na primeira Maratona Mineira de Programação e medalhista de prata na colação de grau. (Aluna do Curso de Ciência da Computação).

A preferência do Programa por estudantes premiados em olimpíadas educacionais ou em premiações relacionadas à pesquisa acadêmica indica que o mérito alcançado contribuiu para sua distinção entre os pares. Um prêmio acadêmico é, sem dúvida, um bem raro, como lembra Bourdieu (2003), capaz de classificar escolarmente seu portador, convertendo-se em recurso simbólico rentável em muitas situações. 


\section{CONSIDERAÇÕES FINAIS}

A população estudada revelou características de intensa seleção escolar. Com efeito, seus percursos foram desenvolvidos em escolas privadas de renome ou, em menor número, em escolas federais, o que possibilitou o sucesso já nas primeiras tentativas de ingresso no ensino superior, quando ainda muito jovens.

Ademais, eles são majoritariamente brancos e membros de famílias com poucos filhos, ambas as características de favorecimento social, e não apenas no Brasil. Ao que se soma sua renda familiar confortável, sua residência em bairros favorecidos e o pertencimento a famílias cujos adultos são altamente escolarizados e, em sua maioria, detentores de profissões de grande prestígio social. Essa biografia justifica sua renúncia ao exercício de atividade remunerada durante o curso superior de graduação, salvo nos casos em que essa estivesse relacionada à obtenção de vantagens acadêmicas, como subsídios oriundos de atividades de pesquisa, monitoria e extensão.

Por parte das famílias, também ficou clara a disposição para os investimentos financeiros necessários, bem como a disponibilidade no acompanhamento da vida escolar dos filhos, certamente fruto da posse de um capital cultural elevado. Por parte dos estudantes, restou a evidência da disposição para o estudo, incluindo o estudo de idiomas, além da mobilização pessoal para os dispositivos para-escolares como cursinhos preparatórios, aulas extras no contra-turno, aulas particulares, com a finalidade de aprovação nos processos seletivos de ingresso na UFMG.

Esse capital escolar constituído no período pré-universitário, aos poucos se metamorfoseou em capital acadêmico, após a travessia dos portões da universidade. Assim, as disposições prévias para o estudo, para o enfrentamento da rotina e competição escolar renderam a eles as propriedades que forjam o aprendiz da ciência, o pesquisador, tal como suposto nos critérios de admissão ao CsF. Tudo isso é franqueado de maneira muito mais provável àqueles que podem se dedicar integralmente aos estudos e à prática científica, pois frequentam o período diurno e não precisam exercer paralelamente uma atividade remunerada.

\section{REFERÊNCIAS}

ADACHI, Ana Amélia Chaves Teixeira. Evasão e evadidos nos cursos de graduação da Universidade Federal de Minas Gerais. Dissertação (Mestrado em Educação). Faculdade de Educação, UFMG, Belo Horizonte. 2009.

BALLATORE, Magaly; BLÖSS Thierry. Láutre réalité du programme Erasmus: affinité sétective entre établissements et reproduction sociale des étudiants. Formation Emploi, n.103, p.57-74, 2008a. 
BALLATORE M. Échanges internationaux em Europe et apprentissages: I'exemple de la mobilité étudiante institutionnalisée para le programme Erasmus", Cahiers de la recherche sur I"éducation et les savoirs. Revue internationale des sciences sociales, n. 3, p.149-166, 2011.

BALLATORE M.; BLÖSS T. Le sens cache de la mobilité des étudiants Erasmus. In: DERVIN F., BYRAM M. (Dir.). Échanges et mobilités académiques. Quel bilan? Paris: L'Harmattan, 2008b. p.17-31.

BARDIN, Lawrence. Análise de Conteúdo. Lisboa:Ed. 70: LDA, 1979.

BOURDIEU, Pierre. Escritos de educação. 5.ed. Petrópolis: Vozes, 2003.

BOURDIEU, Pierre. Efeitos do lugar. In: BOURDIEU, Pierre (Org.) Miséria do mundo. Petrópolis: Vozes, 1997. p. 159- 166.

BRAGA, Mauro. PEIXOTO, Maria do Carmo de Lacerda. Censo socioeconômico e étnico dos estudantes de graduação da UFMG. Belo Horizonte: UFMG, 2006.

BRASIL. Decreto n. 7.642, de 13 de dezembro de 2011. Institui o Programa Ciência sem Fronteiras. Diário Oficial da União: República Federativa do Brasil: DF, 14 dez. 2011

BRITO, Fausto Renato Alves de. Transição demográfica e desigualdades sociais no Brasil. Revista Brasileira de Estudos Populacionais, São Paulo, v. 25, n. 1, p. 5-26, jan./jun. 2008.

CANAAN, Mariana Gadoni. Quem se torna bolsista de iniciação científica na UFMG? Uma análise de fatores que influenciam no acesso à bolsa. 2014. 158f. Dissertação. (Mestrado em Educação). Faculdade de Educação, Universidade Federal de Minas Gerais. Belo Horizonte, 2014.

COMMISSION EUROPÉENNE. Le programme ERASMUS: étudier en Europe et plus encore. Éducation et Formation, 2010.

DAVERnE, Carole. Efeito estabelecimento. In: VAN ZANTEN, Agnès (Coord.). Dicionário de Educação. Petrópolis, RJ: Vozes, 2011.

ERLICH Valerie. Les mobilités étudiantes. Paris: La Documentation Française. 2012.

MALOUTAS, Thomas. Efeitos de vizinhança e desempenhos escolares. In: VAN ZANTEN, Agnès (Org.). Dicionário de educação. Petrópolis: Vozes, 2011.

NOGUEIRA, Maria. Alice Viagens de estudo ao exterior: as experiências de filhos de empresários. In: ALMEIDA, A.M.F. et al. (Org.). Circulação internacional e formação intelectual das elites brasileiras. Campinas: Ed. Unicamp, 2004.

NOGUEIRA, Maria Alice. A construção da excelência escolar - um estudo de trajetórias feito com estudantes universitários provenientes das camadas médias intelectualizadas. Petrópolis: Vozes. 2011.

NOGUEIRA, Maria Alice. Classes médias e escola: novas perspectivas de análise. Currículo sem fronteiras, v. 10, n. 1, p. 213-231, 2010.

NOGUEIRA, Maria Alice. Favorecimento econômico e excelência escolar: um mito em questão. Revista Brasileira de Educação, n. 26, pp. 133-184, 2004. 
NOGUEIRA, Maria Alice; LACERDA, W. G. Os rankings de estabelecimentos de ensino médio e as lógicas de ação das escolas: o caso do Colégio de Aplicação da Universidade Federal de Viçosa. São Paulo: Cortez, 2014.

SCHWARTZMAN, Simon.; CASTRO, Cláudio de Moura. Ensino, formação profissional e a questão da mão de obra. Ensaio, p. 563-624, 2013.

TROGER, Vicent. Ensino técnico e profissionalizante. In: VAN ZANTEN, Agnès (Org.). Dicionário de educação. Petrópolis: Vozes, 2011. p.328-333.

XAVIER de BRITO, Ângela. Formação dos estudantes brasileiros na França/La formation des étudiants brésiliens en France. In: MARTINS, Carlos Benedito de Campos (Org.). DIÁLOGOS entre a França e o Brasil: formação e cooperação acadêmica. Recife, PE: Fundação Joaquim Nabuco: Massangana, 2005. p. 91-105.

Revisão gramatical realizada por: Alayne Carvalho

E-mail: acarvalhocefetaraxa@gmail.com 